\title{
Avaliação Microbiológica de Maionese Contendo Antimicrobiano Natural
}

Izabela Alves Gomes (II), Ana Paula de Oliveira Ribeiro (I), Vanessa

Fiuza de Mello (I), Simone Duarte de Oliveira Costa (I), Eduardo

Henrique Miranda Walter (I), André de Souza Dutra (I), Janine

Passos Lima da Silva (I)

(I) EMBRAPA - Embrapa Agroindústria de Alimentos (Av. das Américas, 29.501 - Rio de Janeiro-RJ), (II) UERJ - Universidade do Estado do Rio de Janeiro (Av. São Francisco Xavier, 524 - Rio de Janeiro-RJ)

\section{Resumo}

A maionese é uma emulsão preparada com óleo vegetal e estabilizada por proteínas existentes na gema do ovo. Em virtude dessa composição vários surtos de infecção alimentar vêm sendo associados ao consumo de preparações culinárias utilizando maionese do tipo caseira (maionese de baixa acidez), isso porque o ovo, um dos principais componentes de sua formulação é um veículo de Salmonella Enteritidis (SE), a principal bactéria envolvida nesses surtos. Para contornar esse problema, óleo essencial de orégano (OEO) pode ser adicionado à formulação de maionese como antimicrobiano natural. Para avaliar a atividade do óleo essencial de orégano em maionese de baixa acidez $(\mathrm{pH} \geq 4,60)$, formulada com gema em pó, armazenada sob refrigeração $\left(10{ }^{\circ} \mathrm{C}\right)$ foi realizada contagem padrão de bactérias aeróbias mesófilas, contagem de fungos filamentosos e leveduras, contagem padrão de bactérias aeróbias psicrotróficas, contagem de coliformes a $45^{\circ} \mathrm{C}$ por NMP e detecção de Salmonella spp. nos tempos $0,7,14,21,28,35$ e 42 dias. Como controle foi avaliada a mesma formulação de maionese, sem OEO. Como resultado, foi possível observar a ausência de Salmonella spp e coliformes a $45^{\circ} \mathrm{C}$ em todos os tempos de análise na maionese com $\mathrm{OEO}$ e na amostra controle. Para fungos filamentosos e leveduras, houve contagem na ordem de 5 log apenas no

\footnotetext{
Referência:

Izabela Alves Gomes, Ana Paula de Oliveira Ribeiro, Vanessa Fiuza de Mello, Simone Duarte de Oliveira Costa, Eduardo Henrique Miranda Walter, André de Souza Dutra, Janine Passos Lima da Silva. Avaliação Microbiológica de Maionese Contendo Antimicrobiano Natural. In: Anais do 12을 Congresso Latinoamericano de Microbiologia e Higiene de Alimentos - MICROAL 2014 [= Blucher Food Science Proceedings, num.1, vol.1]. São Paulo: Editora Blucher, 2014. 
tempo 35 para maionese controle de 2 log para maionese com OEO, no tempo inicial. A contagem de bactérias aeróbias mesófilas foi de $4 \log$ a para maionese com OEO e de $6 \log$ para o controle em todo o período de armazenamento enquanto que a contagem de psicrotróficas foi de $4 \log$ para a amostra controle e para a maionese com OEO, nos tempos 0 a 28 dias, a contagem foi da ordem de $3 \mathrm{log}$, enquanto nos tempos 35 e 42 dias, a contagem caiu para $2 \log$. Com isso, pode-se concluir que a adição de OEO na maionese de baixa acidez aumentou a segurança no consumo do produto por um período de até 42 dias de estocagem a $10^{\circ} \mathrm{C}$, quando comparada com a mesma formulação sem adição de óleo essencial de orégano.

Palavras-Chave: óleo essencial de orégano, Salmonella, maionese de baixa acidez

Agência de Fomento: Embrapa 